\title{
Reflexiones con Jean-Manuel Roubineau
}

Benjamin Cutillas y María del Mar Ortega

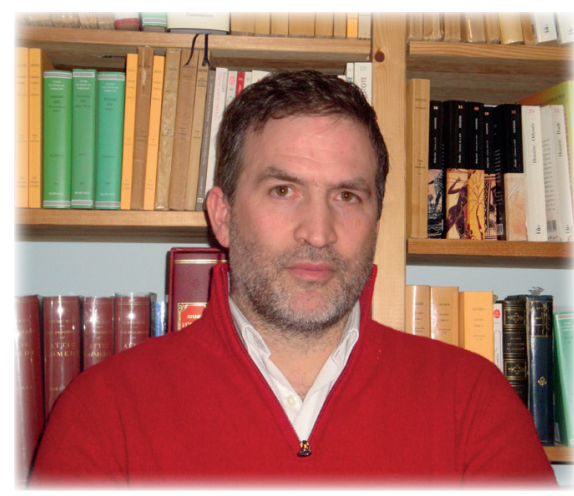

Jean-Manuel Roubineau es profesor de Historia Antigua de la Universidad de Alta Bretaña - Rennes II en la que imparte la asignatura de Sport Grec, y donde desarrolla diversas líneas de investigación en el estudio de la Grecia Clásica, centrándose una de ellas en la Historia del Deporte Griego en la Antigüedad.

Doctorado en la Universidad de Burdeos III, bajo la tutoría de Raymond Descat, defendió su tesis titulada Ateleia. L'exemption fiscale dans le monde grec y fue posteriormente profesor en la Universidad Libre de Bruselas. Como investigador, ha desarrollado diversos estudios centrados principalmente en cuestiones de índole social y económica del mundo griego, destacando temáticas como la mendicidad, la exclusión social o la fiscalidad, aspectos que aborda en la obra que se publicará en agosto de este mismo año Les cités grecques VIe-IIe siècles avant J.-C. Essai d'histoire sociale.

En la actualidad se encuentra inmerso en labores de investigación sobre la práctica deportiva, específicamente en Grecia, pero también en otros ámbitos de la Antigüedad, tomando relevancia entre sus líneas los deportes pesados, tanto en lo que a disciplinas deportivas se refiere como a las figuras de los deportistas.

De esta forma, como antiguos alumnos suyos y conscientes de que este campo del deporte en la Antigüedad es aún un paradigma histórico por descubrir, quisiéramos agradecer de nuevo su disposición y amabilidad para realizar esta entrevista y colaborar con el número de El Futuro del Pasado dedicado al deporte. 
Benjamín Cutillas y María del Mar Ortega (B. C. y M. M. O.): En primer lugar, queríamos agradecerle Sr. Roubineau su disposición a compartir su tiempo con nosotros para hacer esta entrevista. Nos gustaría comenzar esta charla con una pregunta simple pero clave: ¿por qué hacer historia del deporte griego?

Jean-Manuel Roubineau (J-M. R.): El deporte antiguo tiene como peculiaridad que, a primera vista, parece un aspecto más familiar al mundo moderno en comparación a otras prácticas antiguas, debido al lugar ocupado por el deporte y la cultura física en las sociedades contemporáneas. El análisis histórico del deporte griego antiguo permite examinar las continuidades y discontinuidades entre las prácticas antiguas y las modernas.

En este ámbito, la historia del deporte griego puede ser utilizada como una llave de comprensión de aspectos fundamentales de la vida social en el siglo XXI como la cultura corporal, la salud o la competición.

(B. C. y M. M. O.): Estamos también interesados por su historia personal, ¿cómo aparece su interés por este tema y qué trabajos está llevando a cabo en la actualidad?

(J-M. R.): Antes de ser un objeto de investigación, el deporte ha sido para mí un sujeto de enseńanza. El punto de partida fue la realización de una asignatura consagrada a la historia del deporte en la Antigua Grecia en 2008 en el plan del Máster de Historia de la Universidad Libre de Bruselas y después, en 2012, en el marco de la carrera de Historia de la Universidad Rennes II.

No ha sido hasta hace poco cuando he comenzado a orientar más concretamente mis investigaciones en las cuestiones agonísticas. En la actualidad, tengo un interés particular por lo que los griegos llamaban deportes pesados, esencialmente los deportes de combate, interés que no es indiferente al hecho de que yo mismo he practicado el boxeo durante veinte años.

Mis dos principales proyectos de investigación actuales están ligados a estos deportes pesados. En cuanto a libros, me encuentro acabando una biografía del deportista pesado más célebre de la Antigüedad, el luchador Milon de Crotona, que debe aparecer publicada antes del verano de 2016 y, paralelamente, una historia del boxeo en la Antigüedad.

(B. C. y M. M. O.): Por otro lado, el deporte era y es todavía una parte muy importante del complejo entramado de la sociedad actual. ¿Cree usted que a partir del estudio del deporte griego es posible hacer una lectura socio-politica de la civilización griega? ¿Estaba el deporte igualmente considerado en todas las ciudades griegas?

(J-M. R.): Sí, las prácticas deportivas y la ideología deportiva en vigor en las ciudades griegas constituyen un punto de vista propicio para un análisis más general de la ciudad 
como modelo de sociedad. Los sociólogos del deporte han señalado frecuentemente cómo el deporte constituye un puesto de observación privilegiado de la sociedad. Roger Caillois señala que es posible conocer la sociología de una civilización a partir de la configuración de los juegos que se practican en ella; y Norbert Elias considera el deporte como «el laboratorio privilegiado para reflexionar sobre las relaciones sociales y su evolución».

Sobre la cuestión de una eventual diversidad de las concepciones del deporte, de una ciudad a otra es difícil responder de una manera inequívoca. Los valores transmitidos y cultivados en el deporte, al igual que en las prácticas deportivas, parecen relativamente homogéneos de una ciudad a otra. La notoriedad panhelénica de las competiciones sagradas constata la unidad de las concepciones griegas en la materia. Simultáneamente, variaciones locales pudieron existir. Conocemos el caso de los espartiatas que, durante gran parte de la historia antigua, se negaron a practicar el boxeo y el pancracio en competiciones (aunque algunos documentos demuestran que no fue siempre así), bajo el argumento de que los vencidos en esas pruebas estaban obligados a reconocer su derrota, humillación incompatible con la ideología espartiata.

El uso de gimnasios es igualmente variado en espacio y tiempo. Mientras que algunas ciudades pudieron desarrollar un uso exclusivamente deportivo y militar del gimnasio (cf. La ley gimnasiarca de Béroia de Macedonia), otras hicieron progresivamente de los gimnasios lugares educativos en sentido amplio, dejando sitio al lado de la educación física, a una educación filosófica, retórica y científica.

(B. C. y M. M. O.): Este número de El Futuro del Pasado versa también sobre la religión y el deporte. En el caso que nos ocupa, ¿cómo estaba el deporte griego relacionado con la religión?

(J-M. R.): La cuestión de la relación entre el deporte y la religión es muy compleja y ha dado lugar a análisis contradictorios. Sin entrar en detalle en el debate, aquello que sí podemos constatar es que el deporte no era una excepción en cuanto a la omnipresencia de dioses y cultos característica de la sociedad griega.

Los gimnasios, lugar de entrenamiento para el deporte, eran espacios sagrados dedicados a una divinidad -normalmente a Hermes o Heracles-, y en los que se desarrollaban diversos cultos. Las competiciones deportivas tenían lugar en el contexto de los santuarios: los Juegos Olímpicos bajo el amparo del santuario de Zeus Olimpios, los concursos píticos en el ámbito del Santuario de Apolo Pythios, los concursos ístmicos en el de Poseidon Isthmios, etc.

Por tanto, el deporte formaba parte del conjunto de actividades sociales que tenían lugar en las ciudades antiguas y siempre en un contexto religioso, desde las Asambleas a las fiestas familiares, de las sesiones de los tribunales a las competiciones teatrales, hípicas o deportivas. 
(B. C. y M. M. O.): Nos centramos ahora en el complejo mundo de la enseñanza. Usted es profesor de la asignatura de Sport Grec junto con el profesor Jacques Oulhen en el tercer curso de la carrera universitaria de Historia de la Universidad Rennes II. ¿Cómo surgió la idea y por qué se escogió este aspecto de la sociedad griega y no otro?

(J-M. R.): La asignatura de Sport Grec fue creada en 2012 y nació como resultado de uno de esos azares del destino que, a menudo, guían el trabajo científico. Jacques Oulhen había impartido por su parte, durante algunos ańos, una asignatura sobre la historia del deporte destinada a los estudiantes de Ciencias del Deporte de Rennes II y, a la vista de nuestro interés por este tema, decidimos poner en común nuestros conocimientos y unir fuerzas para construir una lectura renovada de la historia del deporte griego.

Mis intereses me guiaban hacia la época arcaica y hacia la representación iconográfica y la literatura. En cambio, el profesor Oulhen estaba más encaminado hacia la época helenística y hacia la documentación epigráfica y arqueológica.

Como podéis ver, nuestras líneas podían complementarse perfectamente, y compartíamos la necesidad de realizar una asignatura entre los dos, aunque estuviera pensada para un solo profesor.

Además, contábamos a nuestro favor con la ventaja de que la temática deportiva siempre suele suscitar un gran interés entre el alumnado. El deporte y su historia son objeto de una demanda social sin duda a la altura de la posición que ocupa el deporte en nuestra sociedad contemporánea.

(B. C. y M. M. O.): También nos interesa hablar un poco sobre la metodología que utilizan en la asignatura, ¿qué criterios se utilizan y bajo qué patrones se desarrolla la asignatura?

La asignatura parte de una idea: el agôn, la competición, que constituye el principal factor explicativo de la práctica deportiva antigua en general, su razón de ser. La lógica intelectual de la asignatura consiste en mostrar cómo la ideología competitiva estructura las concepciones y las prácticas deportivas, y en examinar en qué esta ideología es propiamente deportiva, o, al contrario, en demostrar que es el resultado de una concepción más general de las relaciones sociales. La cuestión de las afinidades entre el deporte y la guerra o entre el atleta y el ciudadano es, en este punto, un tema central.

En detalle, nos esforzamos en abordar las diferentes facetas de la historia del deporte, desde la dietética hasta el erotismo, pasando por los aspectos materiales e institucionales del deporte, las condiciones del espectáculo deportivo y también el lugar que ocupa la violencia en la práctica deportiva. Todo ello utilizando las aportaciones de los modelos de análisis más recientes para tratar de dar a conocer la práctica deportiva antigua, así como la vida del atleta. Para ello, integramos una serie de retratos de la vida de diferentes atletas. 
Aunque la cuestión de los orígenes del deporte y de las evoluciones sufridas por el mismo a lo largo de los siglos se aborde en la asignatura, esta se centra más en la antropología histórica que en la historia stricto sensu. El deporte en la Antigüedad se caracteriza por la gran continuidad de las prácticas y las concepciones que lo estructuran desde la corriente de la época arcaica y hasta la época imperial, continuidad que, a nuestros ojos, justifica este enfoque histórico-antropológico.

(B. C. y M. M. O.): Pero la asignatura no se centra únicamente en el deporte griego, sino que también se explican los precedentes del mismo y se hacen comparaciones con el fenómeno deportivo de otras épocas, como la mesopotámica o la contemporánea. ¿Puede explicarnos un poco estos paralelismos?

(J-M. R.): Al examinar las primeras formas de actividades susceptibles de ser calificadas como deporte en las sociedades mesopotámica o egipcia, el objetivo es reflejar la doble cuestión sobre el eventual origen griego del deporte y la originalidad de los griegos en materia deportiva. La cuestión es saber si debemos comprender el deporte griego como una invención griega o no, y medir hasta qué punto las prácticas deportivas griegas reflejan trazos propios en la cultura griega.

Por otro lado, las comparaciones con las prácticas deportivas modernas permiten definir el perímetro del deporte. ¿De qué hablamos cuando hablamos de deporte? El término en sí mismo ha sido objeto de numerosas redefiniciones desde la mitad del siglo XIX. El riesgo que existe, igual que en Historia, es el de proyectar sobre una práctica histórica representaciones modernas. Sabemos que las definiciones del deporte aportadas por los sociólogos Norbert Elias y Allen Guttmann llegan a negar la naturaleza deportiva de las actividades gimnásticas de los griegos antiguos. La asignatura que propongo junto a Jacques Oulhen se esfuerza en demostrar que este enfoque negacionista del deporte antiguo es erróneo en cuanto a que las prácticas atléticas griegas son de naturaleza deportiva.

(B. C. y M. M. O.): Como asignatura optativa, ¿considera que hay una buena aceptación entre el alumnado? ¿En qué aspectos suelen mostrarse más interesados los alumnos?

La mayor parte de los alumnos inscritos en la asignatura tienen o han tenido alguna relación particular con el deporte. Lo normal es que, a partir de un interés inicial por el deporte como actividad de ocio, se genere un interés por el deporte como objeto de estudio histórico. A lo largo de los años, he podido constatar una curiosidad especial por la historia técnica del deporte antiguo, así como por la deconstrucción de la leyenda del movimiento olímpico moderno, tema que podría dar lugar a otra entrevista entera.

(B. C. y M. M. O.): Pasando un poco hacia la historia de la investigación, el campo del deporte griego tiene una gran tradición en algunos paises europeos, como en Francia, ¿por qué cree que se ha creado esta tradición en Francia con más intensidad que en otros paises? 
(J-M. R.): La tradición francesa en materia de historia del deporte antiguo es relativamente modesta, contrariamente al rol que se podría suponer que ocuparía Francia por su importancia en el renacimiento de los Juegos Olímpicos de 1896. Los grandes nombres de la historia del deporte antiguo del siglo xx, si exceptuamos al epigrafista Louis Robert, son anglosajones y alemanes. Las grandes síntesis de historia del deporte han sido, la mayoría, escritas en esas dos lenguas.

En Francia, aunque los investigadores del campo de la historia del deporte griego son una minoría, podemos citar los trabajos de Jean-Paul Thuillier, especialista en el ámbito del deporte romano y etrusco, y también los de Jean-Yves Strasser, que concentra sus trabajos en el estudio de las prácticas agonísticas griegas de época imperial.

(B. C. y M. M. O.): Todos sabemos que las fuentes son fundamentales para la Historia y, por supuesto, también para conocer el deporte griego. ¿Cuáles son las fuentes de información principalmente utilizadas en esta disciplina?

(J-M. R.): El historiador del deporte se encuentra, en cierta forma, en una posición privilegiada desde el punto de vista documental. Las fuentes son abundantes y muy variadas. Los textos nos proporcionan una ingente cantidad de información, desde poesía hasta tratados médicos, pasando por tratados históricos o filosóficos. Además, la epigrafía agonística es bastante rica, al igual que la documentación iconográfica, que cuenta con estatuas, estatuillas, monedas o, incluso, las pinturas cerámicas. Generalmente, la documentación material proporcionada por las excavaciones de ciertos períodos antiguos es excepcional.

Volviendo a vuestra pregunta, no hay en realidad una fuente principal o más importante que otra. No obstante, es cierto que algunos documentos son especialmente ricos en información, como por ejemplo el Tratado de Gimnástica de Filóstrates, el único de su clase que ha perdurado hasta nuestros días, o la Ley Gimnástica de Béroia de Macedonia, reglamento de gimnasia que nos permite ver en detalle la vida interna de un gimnasio.

(B. C. y M. M. O.): La Arqueología es una disciplina muy importante en el mundo de la investigación actual, pero ¿quépapel juega en el estudio del deporte griego desde su punto de vista?

(J-M. R.): La documentación arqueológica es fundamental a diferentes niveles. Permite construir una historia material del deporte y responder a numerosas cuestiones, desde el aspecto de las líneas de salida de las carreras hasta las condiciones ofertadas a los espectadores en los espectáculos deportivos.

Por tanto, es indispensable tener en cuenta todas las formas documentales disponibles para hacer historia del deporte antiguo. Sería inconcebible en la actualidad llevar de una manera separada una arqueología y una historia del deporte, ya que ambas van de la mano. 
(B. C. y M. M. O.): ¿Cómo ha sido la evolución del estudio del Deporte Griego en estos últimos años? ¿Hay algún aspecto que considere el más importante en este ámbito?

(J-M. R.): Las investigaciones en esta materia han experimentado una gran vitalidad en estos últimos años. Podemos ver un pequeño resumen a través de las publicaciones de la revista Nikephoros, consagrada a la historia del deporte antiguo, o a partir de grandes síntesis como Companion to Sport and Spectacle in Greek and Roman Antiquity, editada por Paul Christesen y Donald Kyle en 2014.

En materia cronológica, la época romana imperial constituye sin duda el campo donde queda más por hacer, aunque trabajos como los de Zahra Newby (Greek Athletics in the Roman World.Victory and Virtue, 2005) o Jason König (Athletics and Literature in the Roman Empire, 2005) han proporcionado en estos últimos años preciosos hitos con los que seguir trabajando.

En cuanto a material documental, el campo que ha conocido la renovación más activa en estos últimos años ha sido sin duda el de las listas de vencedores olímpicos, remarcablemente editadas y analizadas por P. Christesen en una obra que ha marcado un antes y un después (Olympic Victor Lists and Ancient Greek History, 2007).

(B. C. y M. M. O.): En la actualidad, uno de los grandes retos del mundo de la investigación es la divulgación al público de sus resultados, y queremos conocer si esto también sucede con el deporte griego, ¿existe una difusión de este tema fuera de los círculos académicos?, ¿cree que se promueve lo suficiente el interés de aspectos de las civilizaciones antiguas como el deporte?, ¿cómo se podría ayudar a promoverlo desde su punto de vista?

(J-M. R.): Existe una demanda social bastante importante sobre la historia del deporte, a diferencia de otras temáticas de la historia antigua que suscitan poco interés fuera del círculo estrecho de los especialistas en la materia. El interés del público no especialista en el campo de la historia del deporte fluctúa, en parte, en relación al fenómeno de las olimpiadas. La recuperación de las preguntas de historia del deporte durante los cuatro años del período olímpico, y sobre todo en los meses que preceden a los juegos, es un hecho.

Es importante que los científicos se esfuercen en responder a esta demanda social, con el fin de evitar la proliferación de las obras de vulgarización (y también de páginas web), que en su mayoría ofrecen una información de muy mala calidad, y que dan lugar a la difusión de mentiras sobre las prácticas deportivas de la Antigüedad. Es a los especialistas a quienes corresponde el deber de realizar esta misión de divulgación, de dar a conocer al público inexperto la verdadera realidad de una manera adaptada a sus necesidades.

Exposiciones sobre el deporte antiguo son organizadas regularmente, y permiten dar a conocer al gran público una parte de la documentación disponible. Pero los textos 
de divulgación publicados en las colecciones accesibles al gran público no han sido traducidos a numerosas lenguas europeas. Este es uno de los campos de trabajo de la historia del deporte, y una de las misiones al servicio público que los investigadores deben, en mi opinión, realizar en las próximas décadas.

(B. C. y M. M. O.): Para finalizar la entrevista, y agradeciéndole de nuevo su colaboración, quisiéramos plantearle una última cuestión indispensable: ¿cuáles son las perspectivas para el futuro del estudio del deporte griego?

(J-M. R.): El futuro de la historia del deporte griego en la Antigüedad reside probablemente en el desarrollo de un acercamiento pluridisciplinar al deporte, especialmente recurriendo a modelos de análisis que provengan tanto de la antropología, la sociología o la economía, como del análisis de redes sociales e incluso de la psicología histórica.

La buena comprensión de las prácticas y de la concepción deportiva de los griegos antiguos, así como de la puesta en perspectiva de nuestras propias prácticas, creo que pasa por reducir el aislamiento de la disciplina y apostar por el esfuerzo de la multidisciplinaridad. 